\title{
МИКРОФЛОРА КИШЕЧНИКА КУР И ЭКСПРЕССИЯ СВЯЗАННЫХ С ИММУНИТЕТОМ ГЕНОВ ПОД ВЛИЯНИЕМ ПРОБИОТИЧЕСКОЙ И ПРЕБИОТИЧЕСКОЙ КОРМОВЫХ ДОБАВОК
}

\section{И.И. КОЧИШ 1 , О.В. МЯСНИКОВА', В.В. МАРТЫНОВ², В.И. СМОЛЕНСКИЙ1}

Известно, что пробиотические и пребиотические препараты улучшают функционирование кишечника и нормализуют процессы переваривания корма у животных. Колонизация желудочно-кишечного тракта полезной микрофлорой способствует снижению отрицательного влияния патогенных или условно-патогенных микроорганизмов, поддержанию оптимальной кислотности среды, профилактике дисбиоза, стимуляции факторов местного и общего иммунитета. Однако биологические механизмы реализации подобных свойств этих препаратов все еще окончательно не выяснены. Мы оценили воздействие двух российских препаратов - многофункциональной кормовой добавки комплексного действия Профорт ${ }^{\circledR}$ (ООО «Биотроф», Россия), сочетающей качества фермента и пробиотика, и пребиотика Ветелакт («НВЦ Агроветзащита», Россия) на количественный и качественный состав микробиоты кишечника у яичных кур, впервые сопоставив их эффекты с экспрессией генов $\beta$-дефензина 9 (AvBD9), интерлейкина 8 (ILs), галлинацина-10 (Gal-10) и проэнкефалина (PENK), которые связаны с защитными системами организма. В опытах использовали три группы кур (по 20 гол.) кросса Ломанн белый ЛСЛ (Lohmann LSL) с интенсивностью яйцекладки в возрасте 25 нед не менее 95 \% (условия вивария, 2019 год). Кормление птицы осуществляли комбикормом, составленным с учетом требований паспорта на кросс. Введение в рацион опытных групा указанных биологически активных добавок проводили ежедневно в течение 28 сут. Ежесуточно учитывали яйценоскость, еженедельно рассчитывали интенсивность яйцекладки, определяли массу яиц и живую массу птицы. После окончания опыта при помощи NGS секвенирования был определен состав микробиоты слепых отростков кишечника и проведена оценка экспрессии генов $\beta$-дефензина 9 (AvBD9), интерлейкина 8 (ILd), галлинацина-10 (Gal-10) и проэнкефалина $(P E N K)$. Известно, что $\beta$-дефензин 9 и галлинацин-10 относятся к семейству эндогенных пептидов, которые представляют собой важный элемент системы врожденного иммунитета и связующее звено между врожденным (неспецифическим) и приобретенным (адаптивным, специфическим) иммунитетом, проэнкефалин - один из шести опиоидных пептидов, которые регулируют передачу сигналов между клетками и влияют на многие биологические процессы у позвоночных, включая развитие, рост и размножение, а интерлейкин 8 - один из основных провоспалительных хемокинов, образуемый макрофагами, эпителиальными и эндотелиальными клетками, который также играет важную роль в системе врожденного иммунитета. Экспериментально установлено, что наибольшие показатели яичной продуктивности (на 3,33 \% выше контроля, $\mathbf{p}<0,05)$ имели несушки, получавшие пробиотик, при том что их финальная живая масса была минимальной. Скармливание пребиотика приводило к снижению яйценоскости на 0,24$0,45 \%(p>0,05)$, при этом живая масса кур превышала контроль на $0,9 \%(p>0,05)$. Скармливание пребиотика способствовало увеличению общего числа микроорганизмов в содержимом кишечника

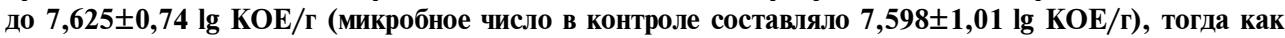
пробиотик снижал количество микроорганизмов до 7,565 $\pm 0,56 \mathrm{lg} \mathrm{KOE} / \Gamma(\mathrm{p}>0,05)$. При этом обе кормовые добавки способствовали увеличению числа бифидо- и целлюлозолитических бактерий в кишечнике и снижали общее количество патогенной и нежелательной микрофлоры на 25$50 \%$. Уменьшение в составе микробиоты доли патогенных и нежелательных микроорганизмов закономерно снижало потребность организма в факторах неспецифической защиты и провоспалительных цитокинах. У получавших кормовые добавки птиц экспрессия гена $\beta$-дефензина 9 была ниже в 3,3-5,0 раза, гена интерлейкина 8 - на 8-36 \% по сравнению с контролем. Наряду со снижением экспрессии генов $\beta$-дефензина 9 и интерлейкина 8 было установлено повышение экспрессии гена галлинацина-10 в $1,48-1,55$ раза и проэнкефалина в 1,11-1,91 раза, что, вероятно, связано с усилением защитных функций организма. Избирательное влияние пробиотика и пребиотика на репродукцию различных видов бактерий в кишечнике, подтвержденное экспрессией генов, связанных с иммунитетом, обосновывает перспективность применения изученных препаратов для повышения резистентности организма птицы и оптимизации функций иммунной системы без ущерба для продуктивности.

Ключевые слова: сельскохозяйственная птица, пробиотик, пребиотик, микробиота кишечника, факторы иммунитета, $\beta$-дефензин 9, интерлейкин 8, галлинацин-10, проэнкефалин, экспрессия гена.

* Исследования проведены при поддержке гранта Правительства Российской Федерации (договор № 14.W03.31.0013 от 20 февраля 2017 года). 
Применение биологически активных кормовых добавок, поддерживающих развитие нормальной микрофлоры кишечника и направленных на стимуляцию защитных сил организма, современной иммунологией рассматривается как один из наиболее перспективных подходов при решении проблемы противостояния инфекционным процессам $(1,2)$.

Кишечник сельскохозяйственных животных и птицы играет важную роль не только в усвоении питательных веществ корма, но и в поддержании иммунной защиты организма $(3,4)$. Барьерная функция ворсинок кишечника (микроворсинчатого цилиндрического эпителия) не может полностью оградить организм от внедрения патогенных бактерий и вирусов без заселения разнообразной полезной микрофлорой. Доказано, что нормофлора стимулирует развитие некоторых тканей слепых отростков кишечника млекопитающих (5). Микробиота кишечника птиц выполняет многочисленные функции по поддержанию гомеостаза и резистентности. Известно, что она принимает участие в нормальном функционировании сердечно-сосудистой, эндокринной, кроветворной, нервной и других систем. Микрофлора кишечника синтезирует аминокислоты, ферменты, антибиотики, витамины и другие ценные для макроорганизма метаболиты $(2,6)$. Микробиота также играет существенную роль в поддержании защитной системы организма $(7,8)$.

Кишечник - один из основных участков внедрения и обитания патогенных микроорганизмов. Поэтому функциональными возможностями кишечника предусмотрен специальный механизм, крайне важный для борьбы с оккупирующей его патогенной микрофлорой (7). Этот механизм можно условно разделить на две группы участвующих в нем факторов. К первой группе относятся факторы, включающие физические барьеры и специальные условия среды (8). В частности, наличие слизистого слоя, защитные свойства муцина, предупреждающего проникновение микроорганизмов и их прикрепление к ворсинкам кишечника, поддержание в тонком кишечнике кислых значений $\mathrm{pH}$, присутствие кислорода, предотвращающего размножение анаэробов, и т.п. $(9,10)$. Вторую группу образуют компоненты иммунной системы - антимикробные пептиды (дефензины), нейропептиды и интерлейкины, которые регулируют синтез муцина и иммуноглобулинов кишечника.

Муцины представляют собой группу гликозилированных белков с молекулярной массой до 20 кДа, играющих ключевую роль в предотвращении проникновения различных патогенов через слизистую оболочку кишечника $(11,12)$. Было показано, что в кишечнике существует определенная связь между микрофлорой и количеством муцина (13).

Антимикробные пептиды - важнейшие компоненты врожденного иммунитета у животных. Эти соединения способны нарушать целостность мембран микроорганизмов (14). $\alpha$-Дефензины характерны только для млекопитающих, у птиц выявлены лишь $\beta$-дефензины (15). У кур идентифицированы четыре вида дефензинов, известных как галлинацины. Галлинацины обладают специфичностью действия в отношении Campylobacter sp., Salmonella sp., Clostridia sp., Escherichia coli. Они подавляют их развитие, вызывают изменения морфологии и лизис (16). Галлинацины экспрессируются в тонком кишечнике, печени, желчном мешке и селезенке кур. Для других недавно изученных дефензинов кур показана тканевая специфичность: AvBD1, AvBD7 и AvBD9 экспрессируются в зобе, AvBD8, AvBD10 и AvBD13 - в кишечнике, AvBD1 и AvBD7 - в селезенке $(14,17,18)$. 
Исследования канадских ученых (19) на цыплятах показали, что выпаивание пробиотика, состоящего из 4 штаммов микроорганизмов ( Lactobacillus acidophilus, Lactobacillus casei, Streptococcus faecium и Saccharomyces cerevisiae) и органических кислот оказал позитивное влияние на морфологию кишечника - длина ворсинок в 12-перстной кишке в опытной группе была больше, чем в контрольной. Экспрессия генов, связанных с иммунитетом, дала противоречивые результаты: у генов AvBD3, IL6, IL10 она повысилась после выпаивания пробиотиков в течение 7 или 14 сут, у генов интерлейкина 12 (IL12) и $\gamma$-интерферона (INF- $\gamma$ ) - была ниже, чем в контрольной группе.

Проэнкефалин, как и другие нейропептиды, не только влияет на регуляцию воспалительного процесса, но и координирует передачу сигналов между клетками, снижает активность клеточной щелочной фосфатазы (20-22). Основная функция интерлейкинов - провоспалительных цитокинов заключается в привлечении дополнительных лейкоцитов из крови к патологическому очагу для повышения сопротивляемости эпителиальных клеток инфекции $(14,23)$.

В большинстве исследований последнего времени, посвященных скармливанию биологически активных кормовых добавок в птицеводстве, оценивалось влияние этих препаратов на продуктивность, здоровье кишечника и экспрессию генов на цыплятах-бройлерах как наиболее удобных и быстро растущих объектах. При этом куры-несушки, производственный цикл использования которых превышает 80 нед, оставались за рамками подобных наблюдений. В то же время поиск препаратов, которые позволят сохранить здоровье кишечника и иммунитет у кур-несушек на протяжении всей жизни, остается насущной проблемой.

В настоящей работе мы впервые в России показали, что скармливание птице пре- и пробиотических добавок может не только влиять на состав микробиоты кишечника, стимулируя рост полезной микрофлоры, но и изменять экспрессию генов, связанных с иммунитетом.

Целью исследования была оценка влияния пребиотического и пробиотического препаратов на показатели продуктивности, количественный и качественный состав микробиоты кишечника и экспрессию генов, связанных с иммунитетом у кур-несушек.

Методика. Исследования проводили в условиях вивария (МГАВМиБ-МВА им. К.И. Скрябина) в 2019 году на курах кросса Ломанн белый ЛСЛ. Кур в 18-недельном возрасте размещали в клетках индивидуального содержания для предварительного определения интенсивности яйцекладки. В возрасте 25 нед из них сформировали 3 группы по 20 гол. с интенсивностью яйцекладки не ниже $95 \%$.

Контрольная птица $(\mathrm{K})$ получала стандартный комбикорм (основной рацион, ОР) в соответствии с рекомендациями для кросса, включающий пшеницу, подсолнечниковый и соевый шроты, травяную муку, подсолнечное масло, витаминные и минеральные добавки. Кормовые добавки применяли в соответствии с инструкциями производителей в течение 28 сут. Куры из I группы (опыт) получали пребиотик Ветелакт («НВЦ Агроветзащита С-П», Россия) на основе 50 \% лактулозы в дозе 0,1 мл/кг живой массы. В рацион кур II группы (опыт) добавляли пробиотик Про-

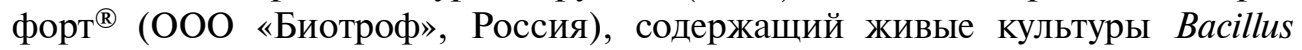
megaterium штамм В-4801 и Enterococcus faecium штамм 1-35 (количество не менее 7,0 lg KOЕ/г из расчета 500 г/т корма). 
В течение опыта яйценоскость учитывали ежесуточно, интенсивность яйцекладки - еженедельно. Массу яиц и живую массу птицы определяли еженедельно на основе индивидуального взвешивания (электронные весы ME-R 326AFU, «Mercury Equipment», Китай).

После окончания опыта по 5 особей из каждой группы подвергли эвтаназии. Фрагменты ткани слепых отростков и их содержимое отбирали для оценки экспрессии генов $\beta$-дефензина 9, галлинацина-10, интерлейкина 8 и проэнкефалина и определения количественного и качественного состава микробиоты слепых отростков кишечника.

Для выделения микробной ДНК использовали набор QIAamp Power Fecal DNA Kit («Qiagen», США) в соответствии с рекомендациями производителя. Количество полученной ДНК измеряли на флуориметре Qubit 3.0 («Thermo Fisher Scientific, Inc.», США).

Общее микробное число (содержание всех микроорганизмов на единицу объема) устанавливали с помощью количественной ПЦР (qPCR) на амплификаторе Light Cycler ${ }^{\circledR} 96$ System («Roche», Швейцария) с применением смеси Maxima SYBR Green/ROX qPCR Master Mix («Termo Fisher Scientific, Inc.», США) с детекцией на основе флуоресцентного красителя SYBR Green; праймеры Eub338 5'-ACTCCTACGGGAGGCAGCAG-3' и Eub518 5'-ATTACCGCGGCTGCTGG-3' («Евроген», Россия). Для определения микробного состава выделенную ДНК обрабатывали с использованием набора 16S Metagenomik Kit и Ion 520 \&Ion 530 ${ }^{\text {тм }}$ Kit-OT2 («Thermo Fisher Scientific, Inc.», США) в соответствии с инструкцией производителя для загрузки на чип для NGS секвенирования, которое осуществляли на приборе Ion Gene Studio ${ }^{\text {TM }}$ S5 System («Thermo Fisher Scientific, Inc.», США). Общее число прочтений при анализе - 2 млн по 300-400 п.н., в среднем по 211000 ридов на образец. Анализ результатов секвенирования для определения микробного состава проводили с помощью сетевого программного продукта Ion Reporter (https://ionreporter.thermofisher.com/ir/) .

Кроме простого сравнения структуры микробиома, определяли число таксонов, взвешенное по относительной численности на основании индекса разнообразия Шеннона и Симпсона (24).

Для изучения экспрессии генов, связанных с иммунитетом у кур, из фрагментов ткани слепых отростков выделяли тотальную РНК. Чистоту препаратов РНК оценивали классическим методом электрофореза в агарозном геле (камера Mini-SubCell GT, «Bio-Rad», США). С использованием РНК из фрагментов ткани слепых отростков кур с помощью обратной транскрипции (набор iScript с реактивами для синтеза кДНК, «Qiagen», США) получали кДНК. Далее при помощи real-time PCR (ПЦР в реальном времени, ПЦР-PB) на амплификаторе LightCycler® 96 System («Roche», Швейцария) с применением набора 2× Quanti Nova SYBR GREEN PCR kit («Qiagen», Австрия) был проведен анализ экспрессии генов, позволяющий обнаружить их активацию в ответ на то или иное воздействие. В качестве референсных использовали ген ТАТА-связывающего белка TBP и ген $\beta$-актина $A C T B L 2 L$ (гены «домашнего хозяйства»; так как температура отжига праймеров у изучаемых генов разная, то были взяты два разных гена «домашнего хозяйства», подходящие по этому параметру). В ПЦР-РВ по каждому из референсных и искомых генов учитывали пороговый цикл флуоресценции $\mathrm{Ct}$.

При обработке результатов использовали методику K.J. Livak и T.D. Shmitgen (25), для чего рассчитывали средние значения пороговых циклов по группе и вычисляли $\Delta \mathrm{Ct}$ (разность значений пороговых циклов между искомым геном и геном «домашнего хозяйства»), а также разность 
значений $\Delta \mathrm{Ct}$ между опытной и контрольной группами $\Delta \Delta \mathrm{Ct}=\Delta \mathrm{Ct} 2-\Delta \mathrm{Ct} 1$. Относительную экспрессию генов рассчитывали по числу пороговых циклов, нормализированных относительно контроля $2^{-\Delta \Delta \mathrm{Ct}}(25)$.

Математическую и статистическую обработку проводили стандартными методами корреляционного и дисперсионного анализа с применением программного обеспечения Excel 2007. Для показателей рассчитывали средние $(M)$ и стандартные ошибки средних $( \pm \mathrm{SEM})$. Полученные экспериментальные результаты проверяли на достоверность различий с использованием калькулятора распределения по $t$-критерию Стьюдента (https://gallery.shinyapps.io/dist_calc/). Различия считали стаистически значимыми при $\mathrm{p}<0,05$. Каждую пробу кДНК исследовали в ПЦР-РВ в трех повторностях. Оценку биологического разнообразия и обработку данных по микробиоте проводили на биоинформатической платформе Qiime 2.0 (https://qiime2.org/).

Результаты. По данным производителя, пробиотическая кормовая добавка Профорт ${ }^{\circledR}$ способна нормализовать микрофлору, повышать сохранность и продуктивность птицы. Пробиотические бактерии препарата Профорт ${ }^{\circledR}$ синтезируют молочную кислоту и витамин $\mathrm{B}_{12}$, который стимулирует регенерацию кишечного эпителия, участвует в синтезе нуклеиновых кислот и ускоряет восстановление антиоксидантов в организме (26). Исследования на бройлерах показали, что скорость роста у цыплят, получавших в качестве кормовой добавки Профорт ${ }^{\circledR}$, оказалась на 6,9 \% выше, чем в контрольной группе, при этом удалось улучшить конверсию корма на $3 \%$ (27). Пребиотический препарат Ветелакт содержит в качестве основного действующего вещества лактулозу - дисахарид галактозы и фруктозы, который в толстом кишечнике расщепляется на низкомолекулярные органические кислоты. Эти кислоты усиливают рост полезных бифидо- и лактобактерий, подавляют размножение потенциально патогенных клостридий и эшерихий, стимулируют перистальтику кишечника, улучшают всасывание солей фосфора и кальция, способствуют выведению ионов аммония (28). Применение препарата Ветелакт при выращивании бройлеров способствовало повышению сохранности поголовья на 2,85\%, живой массы к концу выращивания - на 2,38-3,52 \% при снижении затрат кормов на 1 гол. на 3,3-3,6 \% и на 1 кг прироста бройлеров - на 5,8-7,1 \% (29).

В нашем опыте живая масса кур, яйценоскость и масса яйца между всеми группами различались незначительно (табл. 1).

1. Показатели продуктивности при скармливании пребиотика Ветелакт и пробио-

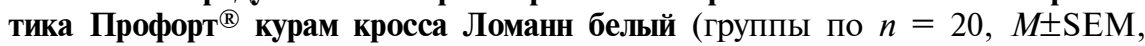
Московская государственная академия ветеринарной медицины и биотехнологии - МВА им. К.И. Скрябина, условия вивария, 2019 год)

\begin{tabular}{|c|c|c|c|}
\hline Показатель & К (контроль) & I группа (пребиотик) & II группа (пробиотик) \\
\hline \multicolumn{4}{|c|}{ До н а ч ал а оп т а (возраст 175 сут) } \\
\hline Живая масса, г & $1434,4 \pm 20,76$ & $1451,1 \pm 26,27$ & $1417,5 \pm 22,44$ \\
\hline Масса яйца, г & $56,19 \pm 0,82$ & $57,24 \pm 1,18$ & $55,13 \pm 0,67$ \\
\hline Яйценоскость, шт. & $28,39 \pm 2,04$ & $27,69 \pm 1,98$ & $28,18 \pm 2,11$ \\
\hline Интенсивность яйцекладки, \% & $95,23 \pm 0,82$ & $95,26 \pm 0,83$ & $95,36 \pm 0,82$ \\
\hline \multicolumn{4}{|c|}{ После окончания опыта (возраст 203 сут) } \\
\hline Живая масса, г & $1468,1 \pm 16,02$ & $1482,13 \pm 29,31$ & $1467,53 \pm 18,22$ \\
\hline Масса яйца, г & $58,19 \pm 0,53$ & $58,05 \pm 1,31$ & $58,91 \pm 0,83$ \\
\hline Яйценоскость, шт. & $21,47 \pm 0,25$ & $21,38 \pm 0,34$ & $22,24 \pm 0,30$ \\
\hline Интенсивность яйцекладки, \% & $93,35 \pm 1,09$ & $92,93 \pm 1,48$ & $96,68 \pm 1,32^{*}$ \\
\hline * Различия с контролем статис & 1чески значимь & $\mathrm{p}<0,05$ & \\
\hline
\end{tabular}

Как видно из таблицы 1, скармливание курам II группы препарата Профорт ${ }^{\circledR}$ привело к увеличению массы яйца на $1,23 \%$ (р > 0,05), интенсивности яйцекладки - на $3,3 \%(\mathrm{p}<0,05)$ по сравнению с контролем. 
Вследствие повышенного расхода энергии на формирование яиц в конце опыта птица этой группы по средней живой массе уступала контролю на $0,03 \%$ (p > 0,05). Пребиотик Ветелакт не оказал значительного влияния на продуктивность и даже привел к некоторому ее снижению в сравнении с контролем - на 0,24-0,45 \% (p >0,05). При этом живая масса кур в опыте незначительно превышала таковую в контроле - на 0,9 \% (p > 0,05).

Вместе с тем пребиотик несколько увеличивал общее число микроор-

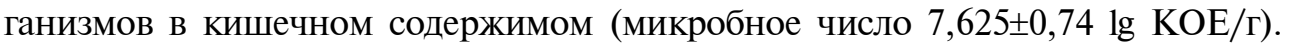
Скармливание пробиотика, наоборот, снижало этот показатель до значе-

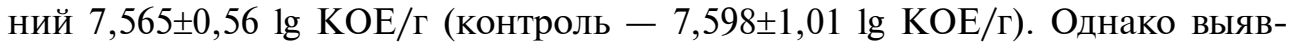
ленные различия между группами были недостоверными и носили характер тенденции.

2. Микробные профили (\%) содержимого слепых отростков кишечника при скармливании пребиотика Ветелакт и пробиотика Профорт ${ }^{\circledR}$ курам кросса Ломанн белый (группы по $n=20, M \pm \mathrm{SEM}$, Московская государственная академия ветеринарной медицины и биотехнологии - МВА им. К.И. Скрябина, условия вивария, 2019 год)

\begin{tabular}{|c|c|c|c|c|c|}
\hline \multirow{2}{*}{ Таксон } & \multirow{2}{*}{ К (контроль) } & \multicolumn{2}{|c|}{ I группа (пребиотик) } & \multicolumn{2}{|c|}{ II группа (пробиотик) } \\
\hline & & всего & $\Delta$ с контролем, \% & всего & $\Delta$ с контролем, \% \\
\hline $\begin{array}{l}\text { Филум Actinobacteria } \\
\text { в том числе: }\end{array}$ & $0,08 \pm 0,03$ & $0,12 \pm 0,10$ & $+50,00$ & $0,18 \pm 0,15$ & $+125,00$ \\
\hline порядок Bifidobacteriales & $0,08 \pm 0,02$ & $0,10 \pm 0,10$ & $+20,00$ & $0,07 \pm 0,05$ & $-12,50$ \\
\hline Филум Bacteroidetes & $32,00 \pm 2,20$ & $27,10 \pm 1,80$ & $-15,40$ & $37,4 \pm 2,74$ & $+16,80$ \\
\hline $\begin{array}{l}\text { Филум Firmicutes } \\
\text { в том числе: }\end{array}$ & $52,40 \pm 2,40$ & $55,00 \pm 2,70$ & $+4,92$ & $47,2 \pm 4,04 *$ & $-9,90$ \\
\hline сем. Lactobacillaceae & $32,20 \pm 3,80$ & $36,90 \pm 4,50$ & $+14,70$ & $23,1 \pm 3,8^{*}$ & $-28,30$ \\
\hline сем. Clostridiaceae & $13,30 \pm 5,30$ & $16,10 \pm 2,30$ & $+20,60$ & $21,4 \pm 2,1^{*}$ & $+60,40$ \\
\hline сем. Ruminococcaceae & $5,86 \pm 0,95$ & $4,78 \pm 0,60$ & $-18,40$ & $7,08 \pm 0,92$ & $+20,80$ \\
\hline род Selenomonadales & $0,12 \pm 0,02$ & $0,14 \pm 0,03$ & $+16,70$ & $0,21 \pm 0,15$ & $+75,00$ \\
\hline $\begin{array}{l}\text { Филум Proteobacteria } \\
\text { в том числе: }\end{array}$ & $15,20 \pm 2,31$ & $17,70 \pm 1,06$ & $+16,50$ & $14,7 \pm 1,66$ & $+39,10$ \\
\hline сем. Enterobacteriacea & $0,75 \pm 0,17$ & $0,35 \pm 0,09$ & $-53,30$ & $0,51 \pm 0,26$ & $-32,00$ \\
\hline Филум Synergistetes & $0,03 \pm 0,01$ & $0,05 \pm 0,01$ & $+66,60$ & $0,03 \pm 0,01$ & 0 \\
\hline $\begin{array}{l}\text { Филум Tenericutes } \\
\text { в том числе: }\end{array}$ & $0,06 \pm 0,03$ & $0,04 \pm 0,02$ & $-33,30$ & $0,09 \pm 0,05$ & $+50,00$ \\
\hline сем. Mycoplasmataceae & $0,04 \pm 0,03$ & $0,00 \pm 0,00$ & $-91,70$ & $0,01 \pm 0,01$ & $-75,00$ \\
\hline Филум Spirochaetes & $0,01 \pm 0,00$ & $0,00 \pm 0,00$ & $-66,60$ & $0,02 \pm 0,02$ & +100 \\
\hline Всего патогены & & & & & \\
\hline и нежелательные & $0,88 \pm 0,10$ & $0,44 \pm 0,07$ & $-50,00$ & $0,66 \pm 0,20$ & $-25,00$ \\
\hline Некультивируемые & $0,23 \pm 0,20$ & $0,02 \pm 0,01$ & $-91,30$ & $0,32 \pm 0,26$ & $-3,10$ \\
\hline
\end{tabular}

Сравнительный анализ микробных профилей в опытных и контрольной группах показал (табл. 2), что бактериальное сообщество содержимого слепых отростков кишечника было представлено шестью основными филумами - Actinobacteria, Bacteroidetes, Firmicutes, Proteobacteria, Synergistetes и Tenericutes. Исключение составили бактерии филума Spirochaetes, которые отсутствовали у птицы из I опытной группы. Бактерии этого филума относятся преимущественно к патогенной и нежелательной микрофлоре, и у здоровых особей (контрольная и опытные группы в эксперименте) ее содержание допускается в минимальных количествах. Род микроорганизмов Lactobacillus важен для микробиоты кишечника, так как предоставляет питательные вещества хозяину и защищает от условно-патогенной микрофлоры, а бактерии порядка Bifidobacteriales могут синтезировать и поставлять в организм витамины (6).

У птицы из I группы, получавшей пребиотический препарат, на $50,00 \%$ увеличилось число бактерий филума Actinobacteria (включая представителей порядка Bifidobacteriales - на 20,00 \%), число бактерий семейства Lactobacillaceae возросло на 14,70 \%, при этом численность целлюло- 
золитических бактерий семейства Ruminococcaceae, а также патогенной и нежелательной микрофлоры сократилась соответственно на 18,40 и 50,00 \%. У птицы из II группы, получавшей пробиотик, количество бактерий филума Bacteroidetes снизилось на 12,50\%, бактерий семейства Lactobacillaceae - на 28,30 \%, при этом количество целлюлозолитических бактерий возросло на 20,80 \%, а численность патогенной и нежелательной микрофлоры сократилась на 25,00 \% (см. табл. 2). В исследованиях, посвященных возрастным изменениям микробиоты у кур-несушек, сообщалось о снижении обилия целлюлозолитических бактерий с возрастом и увеличении представленности бактерий филума Bacteroidetes и лактобактерий (30). В опытах на цыплятах (6) скармливание фитобиотика с растительным экстрактом Macleaya cordata привело к увеличению количества лактобактерий, уменьшению численности патогенной микрофлоры и к снижению экспрессии генов цитокинов и иммуноглобулинов (IL-4, IFN- $\gamma$ ).

Таким образом, в нашем исследовании пребиотик и пробиотик оказали разнонаправленное действие на обилие бифидобактерий и целлюлозолитических бактерий, но одинаково повлияли на общее снижение численности патогенной и нежелательной микрофлоры.

Выполненный нами анализ $\alpha$-разнообразия микробиоты в слепых отростках кишечника кур с помощью индексов Шеннона (контрольная группа $-3,27 \pm 0,10$; I группа $-3,16 \pm 0,10$; II группа $-3,40 \pm 0,04)$ и Симпсона (соответственно $0,84 \pm 0,02 ; 0,81 \pm 0,03$ и $0,86 \pm 0,001)$ показал, что различия между группами статистически не значимы (p > 0,05), что позволяет говорить только о тенденции.

$\beta$-Дефензины и галлинацины птиц играют жизненно важную роль во врожденном противобактериальном иммунитете $(31,32)$. Дефензины, будучи катионными пептидами, активны в отношении бактерий, грибов, оболочечных и безоболочечных вирусов. Иммунные клетки используют дефензины для уничтожения бактерий, поглощенных при фагоцитозе (2).

Гены, связанные с иммунитетом, и праймеры, которые мы использовали при изучении их экспрессии у птицы, получавшей пробиотик и пребиотик, приведены в таблице 3.

3. Праймеры, использованные для оценки экспрессии генов, связанных с иммунитетом у кур кросса Ломанн белый (Московская государственная академия ветеринарной медицины и биотехнологии - МВА им. К.И. Скрябина, условия вивария, 2019 год)

\begin{tabular}{|c|c|}
\hline Ген, белок & Праймер \\
\hline \multicolumn{2}{|l|}{ Гены «домашнего хозяйства»: } \\
\hline \multirow{2}{*}{$A C T B L 2 L(\beta-$-актин) } & F: 5'-ATTGTCCACCGCAAATGCTTC-3' \\
\hline & R: 5'-AAATAAAGCCATGCCAATCTCGTC $-3^{\prime}$ \\
\hline \multirow[t]{2}{*}{ ТВР (ТАТА-связывающий белок) } & F: 5'-GAACATCATGGATCAGAACAACA-3' \\
\hline & R: 5'-ATAGGGATTCCGGGAGTCAT-3' \\
\hline \multirow[t]{2}{*}{$A v B D 9$ (дефензин 9) } & F: 5'-AACACCGTCAGGCATCTTCACA-3' \\
\hline & R: 5'-CGTCTTCTTGGCTGTAAGCTGGA-3' \\
\hline \multirow[t]{2}{*}{ Gal-10 (галлинацин-10) } & F: 5'-GCTCTTCGCTGTTCTCCTCT-3' \\
\hline & R: 5'-CCCAGAGATGGTGAAGGTG-3' \\
\hline \multirow[t]{2}{*}{ PENK (проэнкефалин) } & F: 5'-GCTGGATGAGAACCATCTGC-3' \\
\hline & R: 5'-AGCCTCCGTACCTCTTAGCC-3' \\
\hline \multirow[t]{2}{*}{ IL8 (интерлейкин 8) } & F: 5'-GGAAGAGAGGTGTGCTTGGA-3' \\
\hline & R: 5'-TAACATGAGGCACCGATGTG-3' \\
\hline
\end{tabular}

У птицы, потреблявшей как пробиотик, так и пребиотик, достоверно снижалась экспрессия гена $A v B D 9$ (соответственно в 5,0 и 3,3 раза) (табл. 4). Экспрессия $\beta$-дефензинов в кишечнике индуцируется провоспалительными цитокинами (26), а также микроорганизмами (например, у человека кишечной палочкой, Helicobacter pylori или синегнойной палоч- 
кой) (33). В нашем опыте уменьшение количества патогенных микроорганизмов, судя по всему, снижало потребность в провоспалительных цитокинах, что отразилось на уровне синтеза $\beta$-дефензина 9. Эта закономерность также прослеживалась в показателях экспрессии гена IL8, но в меньшей степени (табл. 5).

4. Экспрессия гена $\beta$-дефензина 9 AvBD9 в тканях слепых отростков кишечника кур кросса Ломанн белый при скармливании пребиотика Ветелакт и пробиотика Профорт ${ }^{\circledR}$ (группы по $n=20, M \pm \mathrm{SEM}$, Московская государственная академия ветеринарной медицины и биотехнологии - MBА им. К.И. Скрябина, условия вивария, 2019 год)

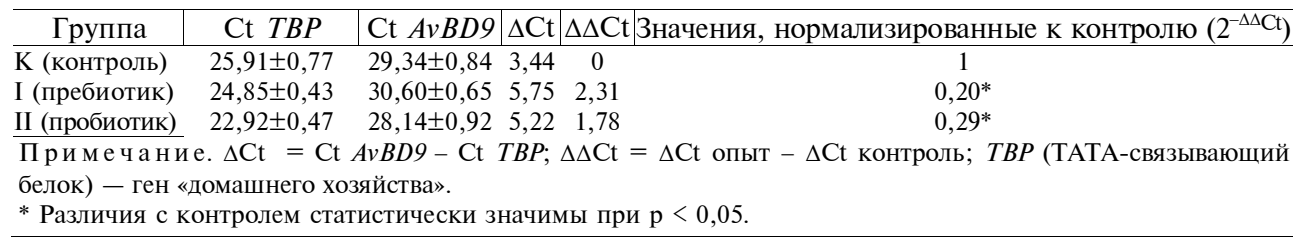

5. Экспрессия гена интерлейкина $8 I L 8$ в тканях слепых отростков кишечника кур кросса Ломанн белый при скармливании пребиотика Ветелакт и пробиотика Профорт ${ }^{\circledR}$ (группы по $n=20, M \pm S E M$, Московская государственная академия ветеринарной медицины и биотехнологии - МВА им. К.И. Скрябина, условия вивария, 2019 год)

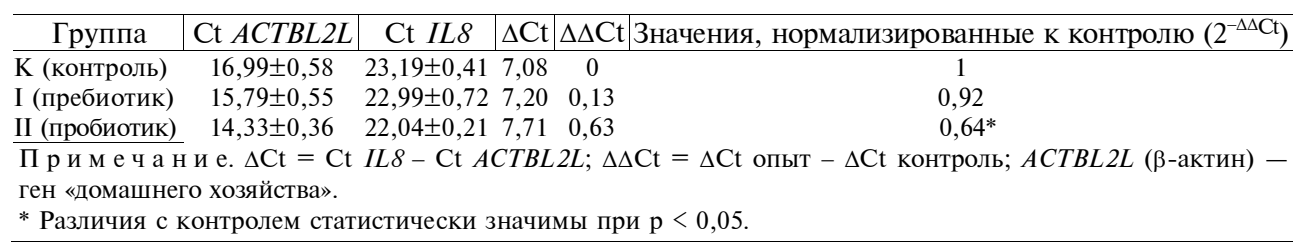

H.R. Haghighi с соавт. (34) в исследованиях на цыплятах-бройлерах показали, что экспрессия генов интерлейкинов IL6, IL 10, IL 12 возрастала при заражении Salmonella typhimurium, однако при скармливании пробиотика она не отличался от таковой в незараженном контроле. Пробиотик повлиял и на экспрессию гена интерферона (INF): при заражении у птицы, получавшей пробиотик, экспрессия оказалась ниже, чем у зараженных особей, не получавших пробиотик (34). В работе А.I. Ateya с соавт. (35) скармливание опытным группам цыплят-бройлеров пробиотика, синбиотика и подкислителя на фоне заражения кишечной палочкой привело к снижению экспрессии ряда генов провоспалительных факторов (Il6, Il8, $A v B D 2, A v B D 9$ ), при этом ген противовоспалительного цитокина IL10 (IL 10) показал резкое увеличение экспрессии по сравнению с незараженным контролем (35).

Нами выявлена положительная корреляция $(r=0,442, \mathrm{p}<0,05)$ между численностью бактерий филума Firmicutes и экспрессией гена $A v B D 9$. Линию аналогичного тренда для экспрессии гена IL 8 строили в полиномиальном уравнении, обнаруженная корреляция оказалась очень низкой и отрицательной $(r=-0,006)$. В работе В.В. Oakley и M.H. Kogut (36) уровень экспрессии цитокинов, как правило, отрицательно коррелировал с относительной численностью различных представителей типа Firmicutes и положительно - с обилием протеобактерий. Корреляции между структурой микробиома и специфической транскрипцией мРНК цитокинов указывают на важное значение микробиома желудочно-кишечного тракта для здоровья и продуктивности птицы и могут быть успешным ин- 
струментом для идентификации бактериальных таксонов с определенными иммуномодулирующими свойствами. В наших исследованиях при скармливании пребиотика численность микроорганизмов филума Firmicutes и протеобактерий возрастала соответственно на 5 и $16 \%$ (р > 0,05), при этом экспрессия цитокина IL8 практически не изменилась (p >0,05), а в случае пробиотика мы отмечали уменьшение обилия тех же микроорганизмов соответственно на $10 \%(\mathrm{p}<0,05)$ и $3 \%(\mathrm{p}>0,05)$ при снижении экспрессии гена $I L 8$ на $36 \%(\mathrm{p}<0,05)$.

Под влиянием стимулов, вызывающих состояние стресса, и в ответ на действие факторов, усиливающих реакцию стресса (кортикотропинрелизинг фактор, цитокины, катехоламины и др.), иммуноциты начинают секретировать опиоиды. Эти пептиды активируют периферические опиоидные рецепторы и вызывают чувство анальгезии, подавляя избыточное возбуждение сенсорных нейронов и облегчая выделение нейропептидов. Опиоидные пептиды, в том числе проэнкефалин, энкефалины, эндорфины, изучаются в настоящее время все более интенсивно (20-22). В исследованиях ученых из Южной Кореи было отмечено значительное колебание экспрессии ряда генов, в том числе гена проэнкефалина, в связи с процессом формирования яйца (37). В таблице 6 приведены полученные нами результаты анализа экспрессии гена проэнкефалина в опытных группах кур. Видно, что, в отличие от цитокинов, экспрессия гена проэнкефалина $(P E N K)$ под воздействием пробиотика повысилась в 1,11 раза $(\mathrm{p}>0,05)$, под воздействием пребиотика - в 1,91 раза $(\mathrm{p}<0,05)$.

6. Экспрессия гена проэнкефалина PENK в тканях слепых отростков кишечника кур кросса Ломанн белый при скармливании пребиотика Ветелакт и пробиотика Профорт ${ }^{\circledR}$ (группы по $n=20, M \pm \mathrm{SEM}$, Московская государственная академия ветеринарной медицины и биотехнологии - MBА им. К.И. Скрябина, условия вивария, 2019 год)

\begin{tabular}{l|c|c|c|c|c}
\hline \multicolumn{1}{c|}{ Группа } & $\mathrm{Ct} T B P$ & $\mathrm{Ct} P E N K$ & $\Delta \mathrm{Ct}$ & $\Delta \Delta \mathrm{Ct} \mid$ & Значения, нормализированные к контролю $\left(2^{-\Delta \Delta C \mathrm{Ct}}\right)$ \\
\hline К (контроль) & $25,91 \pm 0,77$ & $22,63 \pm 0,83$ & $-3,28$ & 0 & 1 \\
I (пребиотик) & $24,85 \pm 0,43$ & $20,64 \pm 0,45$ & $-4,21$ & $-0,93$ & $1,91^{*}$ \\
II (пробиотик) & $22,92 \pm 0,47$ & $19,49 \pm 0,92$ & $-3,43$ & $-0,15$ & 1,11 \\
\hline П р и м е ч а н и е. $\Delta \mathrm{Ct}=\mathrm{Ct} P E N K-\mathrm{Ct} T B P ; \Delta \Delta \mathrm{Ct}=\Delta \mathrm{Ct}$ опыт $-\Delta \mathrm{Ct}$ контроль. TBP (ТАТА-связывающий \\
белок) - ген «домашнего хозяйства». \\
* Различия с контролем статистически значимы при $\mathrm{p}<0,05$. \\
\hline
\end{tabular}

Экспрессия гена галлинацина-10 ( $\mathrm{Gal}$-10) также повысилась (табл. 7), то есть несмотря на то, что этот белок довольно близок к $\beta$-дефензину 9 , реакция оказалась противоположной. Отметим, что в других исследованиях на бройлерах тоже отмечали противоречивые результаты экспрессии $\beta$ дефензина 9 и $\beta$-дефензина $3(19,35)$.

7. Экспрессия гена галлинацина-10 Gal-10 в тканях слепых отростков кишечника кур кросса Ломанн белый при скармливании пребиотика Ветелакт и пробиотика Профорт ${ }^{\circledR}$ (группы по $n=20, M \pm S E M$, Московская государственная академия ветеринарной медицины и биотехнологии - MBA им. К.И. Скрябина, условия вивария, 2019 год)

\begin{tabular}{|c|c|c|}
\hline Группа & $\mathrm{Ct} A C T B L 2 L|\mathrm{Ct} G a l-10| \Delta \mathrm{Ct}|\Delta \Delta \mathrm{Ct}|$ & Значения, нормализированные к контролю $\left(2^{-\Delta \Delta} \mathrm{Ct}\right)$ \\
\hline К (контроль) & $16,99 \pm 0,58 \quad 23,19 \pm 0,415,36 \quad 0$ & 1 \\
\hline I (пребиотик) & $22,99 \pm 0,724,79-0,56$ & 1,48 \\
\hline II (пробиотик) & $14,33 \pm 0,36 \quad 22,04 \pm 0,216,75-0,63$ & 1,55 \\
\hline
\end{tabular}

В наших исследованиях (см. табл. 7) экспрессия гена галлинацина10 при скармливании пребиотика и пробиотика повысилась соответствен- 
но в $1,48(\mathrm{p}>0,05)$ и 1,55 раза $(\mathrm{p}<0,05)$. Всего у кур выявлено 14 генов дефензинов и галлинацинов, обладающих различной антимикробной активностью (38). В исследованиях на бройлерах при заражении Salmonella enterica наблюдалось подавление экспрессии генов галлинацина-10, галлинацина-11, галлинацина-13 и галлинацина-14, тогда как у генов дефензинов 1, 2, 7, 8 и 9 экспрессия осталась без изменения. Дифференциальная экспрессия дефензинов и галлинацинов указывает на особенности участия этих генов в иммунном ответе и различную реакцию не только на возбудителей болезней, но и на кормовые факторы (39).

Формирование нормальной микробиоты, обеспечивающей устойчивости к колонизации и здоровье кишечника, - ключевое условие правильного развития кишечного тракта и полного созревания иммунной системы слизистой оболочки (40). Наше исследование - первая попытка понять взаимодействия между комменсальной микробиотой и экспрессией регуляторных цитокинов в слепой кишке кур-несушек на основе выявления специфических таксонов, обилие которых значительно коррелирует с экспрессией генов цитокинов.

Итак, проведенные нами эксперименты подтвердили тот факт, что скармливание пробиотических и пребиотических добавок положительно воздействует на микрофлору кишечника здоровых кур-несушек при минимальном влиянии этих добавок на продуктивность. Обе кормовые добавки способствовали увеличению числа бифидо- и целлюлозолитических бактерий в кишечнике и снижали общее количество патогенной и нежелательной микрофлоры на 25-50 \%. Изученные биологически активные добавки оказали разнонаправленное действие на функциональную активность генов, связанных с иммунитетом (AvBD9, IL8, PENK, Gal-10) при общей тенденции к стабилизации состояния организма и готовности к подавлению воспалительного процесса. Обнаруженная тенденция значительного роста количества жизненно важных бактерий и аналогичного снижения количества патогенной микрофлоры в кишечнике показывает перспективность применения пробиотика и пребиотика для оптимизации функции иммунной системы, что в конечном итоге улучшит здоровье и повысит продуктивность сельскохозяйственной птицы.

\section{ЛИТЕРАТУРА}

1. Сурай П.Ф., Кочиш И.И., Фисинин В.И., Никонов И.Н., Романов М.Н. Пути поддержания оптимального редокс-баланса в кишечнике птиц: проблемы и решения. Мат. Международной научно-практической конференции «Молекулярно-генетические технологии для анализа экспрессии генов продуктивности и устойчивости к заболеваниям животных», 21-22 ноября 2019 года, Москва). М., 2019: 42-58.

2. Shang Y., Kumar S., Oakley B., Kim W.K. Chicken gut microbiota: importance and detection technology. Frontiers in Veterinary Science, 2018, 10, 5: 254-265 (doi: 10.3389/fvets.2018.00254).

3. Грозина А.А. Состав микрофлоры желудочно-кишечного тракта у цыплят-бройлеров при воздействии пробиотика и антибиотика. Сельскохозяйственная биология, 2014, 6: 46-58 (doi: 10.15389/agrobiology.2014.6.46rus).

4. Фисинин В.И., Лаптев Г. Ю., Никонов И.Н., Ильина Л.А., Йылдырым Е.А. Изменение бактериального сообщества в желудочно-кишечном тракте кур в онтогенезе. Сельскохозяйственная биология, 2016, 51(6): 883-890 (doi: 10.15389/agrobiology.2016.6.883rus).

5. Pickard J.M., Zeng M.Y., Caruso R., Núcez G. Gut microbiota: role in pathogen colonization, immune responses, and inflammatory disease. Immunological Reviews, 2017, 279(1): 70-89 (doi: 10.1111/imr.12567).

6. Huang P., Zhang Y., Xiao K., Jiang F., Wang H., Tang D., Liu D., Liu B., Liu Y., He X., Liu H., Liu X., Qing Z., Liu C., Huang J., Ren Y., Yun L., Yin L., Lin Q., Zeng C., Su X., Yuan J., Lin L., Hu N., Cao H., Huang S., Guo Y., Fan W., Zeng J., Huang P., Zhang Y., Xiao K., Jiang F., Wang H., Tang D., Liu D., Liu B., Liu Y., He X., Liu H., Liu X., Qing Z., 
Liu C., Huang J., Ren Y., Yun L., Yin L., Lin Q., Zeng C., Su X., Yuan J., Lin L., Hu N., Cao H., Huang S., Guo Y., Fan W., Zeng J. The chicken gut metagenome and the modulatory effects of plant-derived benzylisoquinoline alkaloids. Microbiome, 2018, 6: 211 (doi: 10.1186/s40168018-0590-5)

7. Awad W.A., Hess C., Hess M. Enteric pathogens and their toxin-induced disruption of the intestinal barrier through alteration of tight junctions in chickens. Toxins, 2017, 9(2): 60-61 (doi: 10.3390/toxins9020060).

8. Mancabelli L., Ferrario C., Milani C., Mangifesta M., Turroni F., Duranti S., Lugli G.A., Viappiani A., Ossiprandi M.C., van Sinderen D., Ventura M. Insights into the biodiversity of the gut microbiota of broiler chickens. Environmental Microbiology, 2016, 18(12): 4727-4738 (doi: 10.1111/1462-2920.13363).

9. Фисинин В.И., Лукашенко В.С., Салеева И.П., Лаптев Г.Ю., Ильина Л.А., Волик В.Г., Исмаилова Д.Ю. Микрофлора желудочно-кишечного тракта и продуктивность цыплятбройлеров (Gallus gallus L.) под влиянием кормовых добавок из гидролизатов кератин- и коллагенсодержащего сырья. Сельскохозяйственная биология, 2019, 54(2): 291-303 (doi: 10.15389/agrobiology.2019.2.291rus).

10. Павлова Н., Киржаев Ф., Лапинскайте Р. Значение нормальной микрофлоры пищеварительного тракта птиц для их организма. Птицеводческое хозяйство, птицефабрика, 2011, 3: $12-14$

11. Kim Y.S., Ho S.B. Intestinal goblet cells and mucins in health and disease: recent insights and progress. Curr. Gastroenterol. Rep., 2010, 12: 319-330 (doi: 10.1007/s11894-010-0131-2).

12. Tsirtsikos P., Fegeros K., Balaskas C., Kominakis A., Mountzouris K.C. Dietary probiotic inclusion level modulates intestinal mucin composition and mucosal morphology in broilers. Poultry Science, 2012, 91(8): 1860-1868 (doi: 10.3382/ps.2011-02005).

13. Forder R.E., Howarth G.S., Tivey D.R., Hughes R.J. Bacterial modulation of small intestinal goblet cells and mucin composition during early post hatch development of poultry. Poultry Science, 2007, 86(11): 2396-2403 (doi: 10.3382/ps.2007-00222).

14. Terada T., Nii T., Isobe N., Yoshimura Y. Changes in the expression of avian $\beta$-defensins (AvBDs) and proinflammatory cytokines and localization of AvBD2 in the intestine of broiler embryos and chicks during growth. The Journal of Poultry Science, 2018, 55(4): 280-287 (doi: 10.2141/jpsa.0180022).

15. Lynn D.J., Higgs R., Lloyd A.T., O’Farrelly C., Hervé-Grépinet V., Nys Y., Brinkman F.S., Yu P.L., Soulier A., Kaiser P., Zhang G., Lehrer R.I. Avian beta-defensin nomenclature: a community proposed update. Immunology Letters, 2007, 15, 110(1): 86-89 (doi: 10.1016/j.imlet.2007.03.007).

16. Ganz T. Defensins: antimicrobial peptides of innate immunity. Nature Reviews. Immunology, 2003, 3(9): 710-720 (doi: 10.1038/nri1180).

17. Zhao C., Nguyen T., Liu L., Sacco R.E., Brogden K.A., Lehrer R.I. Gallinacin-3, an inducible epithelial $\beta$-defensin in the chicken. Infecion and Immunity, 2001, 69(4): 2684-2691 (doi: 10.1128/IAI.69.4.2684-2691.2001).

18. Hong Y.H., Song W., Lee S.H., Lillehoj H.S. Differential gene expression profiles of $\beta$ defensins in the crop, intestine, and spleen using a necrotic enteritis model in 2 commercial broiler chicken lines. Poultry Science, 2012, 91(5): 1081-1088 (doi: 10.3382/ps.2011-01948).

19. Rodríguez-Lecompte J.C., Yitbarek A., Brady J., Sharif S., Cavanagh M.D., Crow G., CameloJaimes G. The effect of microbial-nutrient interaction on the immune system of young chicks after early probiotic and organic acid administration. Journal of Animal Science, 2012, 90(7): 2246-2254 (doi: 10.2527/jas.2011-4184).

20. Bojnika E., Kleczkowska P., Velasco E.M.F., Corbani M., Babos F., Lipkowski A.W., Benyhe A.M.S. Bioactivity studies on atypical natural opioid hexapeptides processed from proenkephalin (PENK) precursor polypeptides. Comparative Biochemistry and Physiology Part B: Biochemistry and Molecular Biology, 2014, 174: 29-35 (doi: 10.1016/j.cbpb.2014.06.002).

21. Bu G., Cui L., Lv C., Lin D., Huang L., Li Z., Li J., Zeng X., Wang Y. Opioid peptides and their receptors in chickens: structure, functionality, and tissue distribution. Peptides, 2020, 128: 170307 (doi: 10.1016/j.peptides.2020.170307).

22. Majewskia P., Dziwinski T., Pawlak J., Waloch M., Skwarlo-Sontaa K. Anti-inflammatory and opioid-mediated effects of melatonin on experimental peritonitis in chickens. Life Sciences, 2005, 76(17): 1907-1920 (doi: 10.1016/j.lfs.2004.04.062).

23. Lynn D.J., Higgs R., Gaines S., Tierney J., James T., Lloyd A.T., Fares M.A., Mulcahy G., O'Farrelly C. Bioinformatic discovery and initial characterisation of nine novel antimicrobial peptide genes in the chicken. Immunogenetics, 2004, 56(3): 170-177 (doi: 10.1007/s00251-0040675-0).

24. Mohd Shaufi M.A., Sieo C.C., Chong C.W., Gan H.M., Ho Y.W. Deciphering chicken gut microbial dynamics based on high-throughput 16S rRNA metagenomics analyses. Gut Pathogens, 2015, 7: 4 (doi: 10.1186/s13099-015-0051-7).

25. Livak K.J., Shmitgen T.D. Analysis of relative gene expression data using real-time quantitative PCR and the $2^{-\Delta \Delta C t}$ method. Methods, 2001, 25(4): 402-408 (doi: 10.1006/meth.2001.1262). 
26. Йылдырым Е.А., Бражник Е.А., Ильина Л.А., Дубровин А.В., Филиппова В.А, Новикова Н.И., Тюрина Д.Г., Большаков В.Н., Лаптев Г.Ю. Современный пробиотик для здоровья кур. Эффективное животноводство, 2019, 4: 66-67.

27. Меликиди В.Х., Тюрина Д.Г., Селиванов Д.Г., Новикова Н.И. Метаболиты пробиотических бактерий отвечают за эффективность действия пробиотика. Птицеводство, 2019, 910: 45-47 (doi: 10.33845/0033-3239-2019-68-9-10-45-47).

28. Околелова Т.М., Енгашев С.В., Салгереев С.М. Клеточная усталость кур-несушек: причины и профилактика. Ветеринария, 2017, 11: 15-19.

29. Околелова Т.М., Енгашев С.В., Салгереев С.М., Лесниченко И.Ю. Российские препараты для производства экологически безопасной продукции. Эффективное животноводство, 2018, 3: 46-49.

30. Videnska P., Sedlar K., Lukac M., Faldynova M., Gerzova L., Cejkova D., Sisak F., Rychlik I. Succession and replacement of bacterial populations in the caecum of egg laying hens over their whole life. PLoS ONE, 2014, 9(12): 115-142 (doi: org/10.1371/journal.pone).

31. Zhang G., Sunkara L.T. Avian antimicrobial host defense peptides: from biology to therapeutic applications. Pharmaceuticals, 2014, 7(3): 220-247 (doi: 10.3390/ph7030220).

32. Кочиш И.И., Лаптев Г.Ю., Новикова Н.И., Смоленский В.И., Ильина Л.А.,Тюрина Д.Г., Филлипова В.А., Богданова Д.М., Дубровин А.В., Соболев Д.В., Йылдырым Е.А., Шихбабаев Э.У. Способ кормления сельскохозяйственной птицы, способствующий увеличению экспрессии бета-дефензинов. Патент России № 2689 709, 2018. Опубл. 2019.05.28.

33. Bauer B., Wex T., Kuester D., Meyer T., Malfertheiner P. Differential expression of human beta defensin 2 and 3 in gastric mucosa of Helicobacter pylori-infected individuals. Helicobacter, 2013, 18(1): 6-12 (doi: 10.1111/hel.12000).

34. Haghighi H.R., Abdul-Careem M.F., Dara R.A., Chambers J.R., Sharif S. Cytokine gene expression in chicken cecal tonsils following treatment with probiotics and Salmonella infection. Veterinary Microbiology, 2008, 126(1-3): 225-233 (doi: 10.1016/j.vetmic.2007.06.026).

35. Ateya A.I., Arafat N., Saleh R.M., Ghanem H.M., Naguib D., Radwan H.A., Elseady Y.Y. Intestinal gene expressions in broiler chickens infected with Escherichia coli and dietary supplemented with probiotic, acidifier and synbiotic. Veterinary Research Communications, 2019, 43(2): 131-142 (doi: 10.1007/s11259-019-09753-z).

36. Oakley B.B., Kogut M.H. Spatial and temporal changes in the broiler chicken cecal and fecal microbiomes and correlations of bacterial taxa with cytokine gene expression. Frontiers in Veterinary Science, 2016, 3: 11 (doi: 10.3389/fvets.2016.00011).

37. Jeong W., Lim W., Kim J., Ahn S.E., Lee H.C., Jeong J.W., Han J.Y., Song G., Bazer F.W. Cell-specific and temporal aspects of gene expression in the chicken oviduct at different stages of the laying cycle. Biology of Reproduction, 2012, 86(6): 172 (doi: 10.1095/biolreprod.111.098186).

38. Mowbray C.A., Niranji S.S., Cadwell K., Bailey R., Watson K.A., Hall J. Gene expression of AvBD6-10 in broiler chickens is independent of AvBD6, 9, and 10 peptide potency. Veterinary Immunology and Immunopathology, 2018, 202: 31-40 (doi: 10.1016/j.vetimm.2018.06.007).

39. Ramasamy K.T., Verma P., Reddy M.R. Differential gene expression of antimicrobial peptides $\beta$ defensins in the gastrointestinal tract of Salmonella serovar Pullorum infected broiler chickens. Veterinary Research Communications, 2012, 36(1): 57-62 (doi: 10.1007/s11259-011-9512-8).

40. Sommer F., Bäckhed F. The gut microbiota - masters of host development and physiology. Nature Reviews Microbiology, 2013, 11(4): 227-238 (doi: 10.1038/nrmicro2974).

\author{
1ФГБОУ ВО Московская государственная академия \\ ветеринарной медицины и биотехнологии- \\ МВА им. К.И. Скрябина, \\ 109472 Россия, г. Москва, ул. Академика Скрябина, 23, \\ e-mail: prorector@mgavm.ru, omyasnikova71@gmail.com, \\ Smolensky-vgnki@mail.ru $\square$; \\ 2ГОУ ВО Московский государственный \\ областной университет, \\ 141014 Россия, Московская обл., г. Мытищи, \\ ул. Веры Волошиной, 24, \\ e-mail: martynov.vik@gmail.com
}

Sel'skokhozyaistvennaya biologiya [Agricultural Biology], 2020, V. 55, № 2, pp. 315-327

\title{
INTESTINAL MICROFLORA AND EXPRESSION \\ OF IMMUNITY-RELATED GENES IN HENS AS INFLUENCED BY PREBIOTIC AND PROBIOTIC FEED ADDITIVES
}

\author{
I.I. Kochish ${ }^{1}$, O.V. Myasnikova1, V.V. Martynov' ${ }^{2}$, V.I. Smolensky1
}


${ }^{1}$ Skryabin Moscow State Academy of Veterinary Medicine and Biotechnology, 23, ul. Akademika K.I. Skryabina, Moscow, 109472 Russia, e-mail prorector@mgavm.ru, omyasnikova71@gmail.com, Smolensky-vgnki@mail.ru (凹 corresponding author);

${ }^{2}$ Moscow Region State University, 24, ul. Very Voloshinoi, Mytishchi, Moscow Province, 141014 Russia, e-mail martynov.vik@gmail.com

ORCID:

Kochish I.I. orcid.org/0000-0001-8892-9858

Myasnikova O.V. orcid.org/0000-0002-9869-0876

Martynov V.V. orcid.org/0000-0003-1784-3429

The authors declare no conflict of interests

Acknowledgements:

Supported financially by the Government of the Russian Federation (Agreement No. 14.W03.31.0013 of February 20, 2017).

Received February 4, 2020

doi: 10.15389 /agrobiology.2020.2.315eng

\section{Abstract}

It is known that probiotic and prebiotic feed additive improve the function of the intestines and lead to normal the processes of digestion of food for animals. Colonization of the gastrointestinal tract with beneficial microflora helps to reduce the negative impact of pathogenic or conditionally pathogenic microorganisms, maintain optimal acidity of the gut, prevent dysbiosis, and stimulate local and general immune factors. However, the biological mechanisms for the implementation of such properties of these drugs are still not fully understood. We evaluated the effect of two Russian products, the multifunctional feed additive Profort ${ }^{\circledR}$ (Biotrof LLC, Russia), combining the qualities of an enzyme and probiotic, and the prebiotic feed additive Vetelact (SVC, Agrovetzashchita, Russia) on the quantitative and qualitative composition of the intestinal microbiota in egg layers to compare the effect of these feed additives on the intestinal microbiota with the expression of the $\beta$-defensin 9 (AvBD9), interleukin 8 (IL8), gallinacin-10 (Gal-10) and proenkephalin (PENK) genes that are associated with immune systems. Lohmann white LSL hens with an egg laying intensity of at least $95 \%$ at the age of 25 weeks were used in the experiment (the conditions of vivarium, 2019). The hens were assigned to three groups (20 birds each). Feeding the birds was carried out with mixed feed, the feed specification were calculated according manual from Lohmann Tierzucht. Birds of the control group received only mixed feed. Birds of the experimental groups were also fed with biological additives for 28 days. The egg production was recorded daily, the egg laying intensity, egg weight and body weight were recorded weekly. After the termination of the experiment, the composition of the microbiota of the blind processes of the intestine was determined using NGS sequencing and the expression levels of the $\beta$-defensin $9(A v B D 9)$, interleukin $8(I L 8)$, gallinacin-10 ( Gal-10), and proenkephalin $(P E N K)$ genes were assessed. It is known that $\beta$-defensin 9 and gallinacin-10 belong to the family of endogenous peptides, which are an important element of the innate immunity system and a link between innate (non-specific) and acquired (adaptive, specific) immunity, proenkephalin is one of six opioid peptides that regulate signaling between cells and affect many biological processes in vertebrates, including development, growth and reproduction, and interleukin 8 is one of the main pro-inflammatory chemokines formed by macrophages, epithelial and endothelial cells which also plays an important role in the innate immune system. It was established that the hens receiving probiotic had the highest egg productivity $(3.33 \%$ higher than the control, $\mathrm{p}<0.05)$, while their final body weight was minimal. Feeding a prebiotic led to a $0.24-0.45 \%(\mathrm{p}>0.05)$ decrease in egg production with the body weight $0.9 \%(\mathrm{p}>0.05)$ higher compared to the control. Feeding the prebiotic contributed to an increase in the total number of microorganisms in the intestinal contents to $7.625 \pm 0.74 \mathrm{lg} \mathrm{CFU} / \mathrm{g}$ (the microbial number in the control was $7.598 \pm 1.01 \mathrm{lg} \mathrm{CFU} / \mathrm{g}$ ), while the feeding with probiotic reduced the number of microorganisms to $7.565 \pm 0.56 \mathrm{lg} \mathrm{CFU} / \mathrm{g}$ $(p>0.05)$. Both feed additives contributed to an increase in the number of bifidobacteria and cellulolytic bacteria in the intestine and reduced the total amount of pathogenic and undesirable microflora by $25-50 \%$ vs. control. A decrease in the proportion of pathogenic and undesirable microorganisms in the composition of microbiota naturally reduced the body's need for non-specific defense factors and pro-inflammatory cytokines. In the birds receiving feed additives, the expression of the $\beta$ defensin 9 gene was 3.3-5.0 times lower, and the interleukin $8(I L 8)$ gene expression level was reduced by 8-36\% compared to the control. Along with a decrease in the expression of $\beta$-defensin 9 and interleukin- 8 genes, a 1.48-1.55-fold increase in the expression of the gallinacin-10 gene and 1.11-1.91-fold increase in proenkephalin were established, which is probably associated with strengthening the protective functions of the body. The selective effect of probiotic and prebiotic on the reproduction of various types of bacteria in the intestine, confirmed by the negative expression of genes associated with immunity, justifies the promise of using the studied products to increase the resistance of poultry and normalize functions of the immune system without compromising of poultry performance.

Keywords: commercial poultry, probiotic, prebiotic, intestinal microbiota, immune factors, $\beta$-defensin 9 , interleukin 8 , gallinacin-10, proenkephalin, genes expression. 